\section{Changes in Chloroplast Pigments in Leaves during} Senescence

Loss of chlorophyll in senescent leaves is a general phenomenon, and various views have been put forward to explain how chlorophyll disappears as the leaf yellows. The possibilities recognized are: (1) the decomposition of chlorophyll into its basic components and the transference of the latter to places of storage; and (2) the transformation of chlorophyll into certain substances likely to function during senescence.

Meyer ${ }^{1}$ suggested that chlorophyll decomposes and is then borne away, while the yellow pigments remain as they were in the leaf. His conclusion having been reached without any quantitative estimations, it can only be regarded as tentative. Swart ${ }^{2}$ concludes that chlorophyll is decomposed and nitrogen translocated. Stoklasa, Senft and Sebor ${ }^{3}$ believe that the autumnal changes of colour depend on the hydrolytic fission of chlorophyll and the formation of phæophytin and phosphatids.

In the course of our studies on the seasonal variations in the chloroplast pigments of tropical plants, the data obtained pointed to the possibility of a conversion of chlorophyll to carotenoids during the yellowing of the leaves.

Leaves of Bassia latifolia examined passed through the following stages during senescence; after dark green, bright green 10 days, green 15 days, yellow green-yellow 6 days (at this stage yellow spots appeared along the marginal veins), almost yellow 2 days and then bright yellow. The results of the pigment analysis at these successive stages are set forth in the accompanying table.

\begin{tabular}{|c|c|c|c|}
\hline Stage of senescence & Chlorophyll* & Carotin* & Xanthophyll* \\
\hline Dark green & $23 \cdot 68$ & $9 \cdot 34$ & $7 \cdot 21$ \\
\hline $\begin{array}{l}\text { Bright green ( } 5 \text { days } \\
\text { after the dark green } \\
\text { stage) }\end{array}$ & $17 \cdot 95$ & $10 \cdot 41$ & $7 \cdot 91$ \\
\hline $\begin{array}{l}\text { Green (15 days after } \\
\text { the dark green stage) }\end{array}$ & $11 \cdot 34$ & $11 \cdot 05$ & $8 \cdot 34$ \\
\hline $\begin{array}{l}\text { Yellow green-yellow } \\
(30 \text { days after the } \\
\text { dark green stage) }\end{array}$ & $6 \cdot 25$ & $16 \cdot 05$ & $11 \cdot 72$ \\
\hline $\begin{array}{l}\text { Almost yellow ( } 36 \text { days } \\
\text { after the dark green } \\
\text { stage) }\end{array}$ & $1 \cdot 16$ & $17 \cdot 25$ & $14 \cdot 21$ \\
\hline $\begin{array}{r}\text { Shedding (42 days after } \\
\text { the dark green stage) }\end{array}$ & 0.00 & $3 \cdot 45$ & $2 \cdot 10$ \\
\hline
\end{tabular}

* Expressed as mgm. per $10 \mathrm{gm}$. of dry weight.

The chlorophylls $(a+b)$ were determined by the procedure recently developed by us ${ }^{4}$ : the measurement of light absorption of an alcoholic extract (80 per cent methyl alcohol) of plant pigments within a narrowly defined region of the spectrum, for which the chlorophylls $(a+b)$ possess a marked absorption, while the absorption of the other pigments is infinitesimal. Carotin and xanthophyll were determined by a new spectrophotometric method, a description of which will appear shortly.

The data indicate that during the different stages of the yellowing of the leaf, as chlorophyll decreases, there is a corresponding rise in the carotenoids, the increase in carotin being more than that in xanthophyll. Further, at the shedding stage of the leaf, the carotenoids disappear almost completely.

On a consideration of the results presented here, in conjunction with the experimental results of Ewart ${ }^{5}$ that carotin is present in greater amounts when chlorophyll is absent and carotin apparently decreases as chlorophyll increases, it appears that the increase in carotenoids during the yellowing of the leaves is a consequence of the disappearance and transformation of chlorophyll.

\section{B. N. SINGH.}

N. K. Anantha Rao.

Plant Physiological Laboratories,

Institute of Agricultural Research, Benares Hindu University. Sept. 18.

Meyer, A., Flora, 85 (1918).

${ }^{2}$ Swart, N., Jena (1914).

${ }^{3}$ Stoklasa, J., Senft, E., and Sebor, J., J. Chem, Soc., 106 (1914).

- Singh, B. N., and Anantha Rao, N. K., Curr. Sci., 8, 416 (1937).

${ }^{5}$ Ewart, A. J., Proc. Roy. Soc. Victoria, 30, 187 (1918).

\section{River Flow around Bends}

IN two paragraphs in the News and Views columns of NATURE of September 18, a lecture on "Rivers", delivered in connexion with the recent meeting of the British Association by Mr. R. Kay Gresswell, was summarized. A statement made in this report requires comment on the ground that, while un. doubtedly representing a view held by a considerable number of competent geographers, geologists, and others, it is at variance with the facts as established experimentally many years ago by the late Prof. James Thomson.

The statement was as follows: "In turning a corner, the speed on the outside of the curve is always greater than that on the inside. This results in the water on the outside being able to take an additional load and so erode the bank." The erosion of the bank is incontrovertible; it is universally in evidence, but Prof. Thomson's investigations showed that the erosion is not due, as alleged, to greater velocity on the outside of the curve. On the contrary, the velocity there is less than on the inner side of the bend.

Prof. Thomson's explanation of the matter is con. tained in papers contributed to the Royal Society (Proc., 26, 356) and the Institution of Mechanical Engineers (Proc., p. 456; 1879). I have not the original papers at hand, but $I$ venture to quote as follows from the authoritative article on "Hydromechanics" by the late Prof. W. Cawthorne Unwin, in the "Encyclopedia Britannica" (ninth edition, 1881, vol. xii) :

"When water moves round a circular curve under the action of gravity only, it takes a motion like that in a free vortex. Its velocity is greater parallel to the axis of the stream at the inner than at the outer side of the bend. Hence the scouring at the outer side and the deposit at the inner side of the bend are not due to mere difference of velocity of flow in the general direction of the stream; but, in virtue of the centrifugal force, the water passing round the bend presses outwards, and the free surface in a radial cross section has a slope from the inner side upwards to the outer side (Fig. 1). For the greater part of the water flowing in curved paths, this difference of 